\title{
Políticas de regulação na educação: a organização da escola em ciclos em Goiânia (1998-2008).
}

\section{Regulatory policies in education: the organization of schooling in cycles in the State of Goiânia, Brazil (1998-2008)}

\author{
Maria Augusta Peixoto Mundim**
}

Resumo: O presente trabalho analisa a organização da escola em ciclos em Goiânia à luz dos processos de regulação das políticas educacionais empreendidos no Brasil a partir da década de 1990. A investigação de natureza teórico-bibliográfica beneficiouse das análises da regulação social realizadas no campo da economia e da sociologia política tendo como referência o quadro teórico-metodológico desenvolvido por Marx e fertilizado por Gramsci. Presume-se que há, no cenário atual, novas formas de regulação social que em seus desdobramentos têm reverberado na regulação das políticas educacionais e, em certa medida, têm informado princípios para novas formas de organização da escola.

Palavras-chave: Regulação social. Políticas educacionais. Escola em ciclos.

\begin{abstract}
The present article analyzes the organization of schooling in cycles in the State of Goiânia, Brazil, in the light of the regulation of education policies that took place in the country from the 1990's onwards. Our theoretical-bibliographical research took advantage of former analysis of the social regulation performed in the fields of Economy and Political Sociology, using as reference the theoretical-methodological framework developed by Marx and perfected by Gramsci. It is presumed that, in the current scenario, that are new forms of social regulation that, in its developments, have echoed in the regulation of educational policies and that, in a sense, have informed principles for new forms of organization of the school.
\end{abstract}

Keywords: Social regulation. Educational policies. Schooling organized in cycles.

\footnotetext{
* Uma versão preliminar desse texto foi apresentada no I Congresso Ibero-Brasileiro e VI Congresso LusoBrasileiro de Política e Administração da Educação, realizado na Espanha e em Portugal, em 2010.

** Professora da Universidade Federal de Goiás. E-mail: <mariaugusta.peixoto@gmail.com>
} 


\section{Introdução}

O presente artigo apresenta uma síntese de uma pesquisa sobre os nexos constitutivos da organização da escola em ciclos na sua relação com as novas formas de regulação das políticas educacionais em curso no Brasil, particularmente a partir da década de 1990 . O que se pretende é tomar a regulação como movimento oriundo dos processos de intervenção do Estado, compreendendo que a intervenção, articulada a momentos de não intervenção podem se constituir em fatores imprescindíveis à regulação. Convém esclarecer ainda que não se trata de tomar a regulação apenas no aspecto da oposição entre regulação do Estado e regulação do mercado. Parte-se do princípio de que os processos de intervenção do Estado na educação, aqui denominados novas formas de regulação das políticas, incluem, em muitos momentos, a incorporação da lógica de mercado, da lógica do voluntariado, da lógica humanista e outras diferentes e sofisticadas estratégias de intervenção para a realização da precípua finalidade de manutenção da coesão social e hegemonia de uma determinada classe.

No contexto das novas formas de regulação das políticas, inscritas particularmente, por meio do amplo processo de reformas instituídas a partir dos anos de 1990, encontram-se as mudanças nos processo de organização da escola, seja no âmbito da gestão, do currículo e da avaliação. Como emblema dessas mudanças encontra-se a organização da escola em ciclos.

\section{Regulação social reformas do Estado e da educação}

O processo de mundialização do capital, com suas consequentes alterações nos centros de poder, particularmente no que tange à redefinição do papel do Estado, tem provocado alterações significativas no âmbito do contrato social. Tem imprimido um acelerado processo de flexibilização/desregulamentação das relações de trabalho, uma grande centralização do capital e descentralização das operações, possibilitados pela inserção das novas tecnologias no âmbito da produção e reprodução. Em contraposição, este processo tem provocado uma grande concentração urbana, ampliado as desigualdades sociais criando um verdadeiro fosso entre ricos e pobres, condenado milhões de assalariados e jovens ao desemprego estrutural, destruído valores morais e éticos e impelido uma grande massa à pobreza, à degradação humana e à decadência social (CHESNAIS, 1996).

Em decorrência desses e de outros aspectos, pode-se conjecturar que a coesão social, no seu processo de regulação social, apresenta fissuras que podem colocar em risco a continuidade do processo de acumulação nessa particularidade histórica. Desse modo, são necessários ajustes, reformas e estratégias políticas 
que envolvam toda a sociedade no sentido de criar condições para a continuidade da acumulação e da reprodução do capital, minimizando os riscos deste processo. Por conseguinte, encontram-se em curso novas formas de regulação, particularmente por meio das políticas educacionais destinadas a minimizar os efeitos perversos desse processo na esfera social.

São metas centrais desse processo as políticas de desestatização, desregulamentação, privatização, descentralização e "modernização". Com a abertura para o livre fluxo do capital, elas generalizaram-se e passaram a constituir o novo cenário internacional. Sob a retórica da flexibilidade, tais políticas tem se apresentado como verdadeira e bem articulada tendência e, embora pareçam uníssonas, têm se concretizado de modo contraditório nos diversos países do mundo. Essa contradição pode ser observada tanto na variedade das formas pelas quais essas políticas se materializam em cada contexto quanto na polarização com que atuam, muitas vezes, no contexto de uma mesma instituição. Conforme evidenciado em vários estudos, isso se confirma pela presença, cada vez mais frequente, de estratégias e medidas que associam elementos de centralização-descentralização, regulamentação-desregulamentação, autonomia associada a formas de controle, privatização na forma do público não estatal, desestatização com subsídios estatais, etc. (OLIVEIRA, 2005; MAROY, 2006). Diante da divergência de estratégias, cabe ressaltar que se deve atentar para não tratar essas tendências de forma generalizada, como um modelo hegemônico.

Para melhor compreender essa questão no quadro mais amplo do contexto da regulação social no capitalismo, buscou-se a apropriação de algumas das análises do processo de regulação social desenvolvidas no campo da economia e da sociologia política, tidas como importantes e pertinentes para o desvelamento dos processos de regulação no campo das políticas educacionais. A despeito da complexidade e da heterogeneidade dos trabalhos desenvolvidos sobre esta temática, foram priorizados os aspectos da teoria que permitiram a apreensão das novas formas de regulação nas políticas educacionais e os seus desdobramentos nas novas formas de organização da escola, de maneira específica na organização da escola em ciclos. Neste contexto, buscou-se apreender tais concepções sem perder de vista o quadro teórico-metodológico desenvolvido por Marx e fertilizado por Gramsci.

Quanto às formas assumidas pelo Estado, cabe afirmar que as análises da regulação empreendidas pelos autores da denominada Escola Francesa da Regulação (EFR), particularmente as de Aglietta (1979), Boyer (1990) e Lipietz (1988), atribuem um papel preponderante às suas intervenções. Não se trata, entretanto, de vincular mecanicamente as mudanças no regime de acumulação e no modo de regulação às mutações do Estado, mas, sobretudo, de apreender na complexidade dessas relações a gênese do seu contraditório movimento e suas consequentes implicações. 
Os vínculos existentes entre as intervenções do Estado e a dinâmica econômica são múltiplos e de natureza complexa. Numa correlação de forças, o Estado está sempre submetido a processos contraditórios: seja na manutenção da acumulação ou na legitimação das relações sociais existentes. De acordo com Boyer (1990, p. 78), “[...] circunscrito ou inserido, o Estado faz, portanto, parte integrante da definição, da montagem e depois da crise de todo e qualquer regime de acumulação." Desse modo, pode-se afirmar que a regulação nas suas diferentes formas se encontra condicionada à ação do Estado. Em razão disso é que foi possível associar a passagem de um regime de acumulação a outro, também a uma modificação das formas de Estado.

Ademais, um conjunto de características organizacionais, concernente à flexibilização da produção e à sua convergência e extensão para instituições em todas as esferas da sociedade, denota mudanças no atual processo de acumulação e de regulação capitalista. Tal processo, entretanto, não pode ser compreendido de uma forma totalizante. Embora seja possível constatar a flexibilidade como uma tendência, rigidez e flexibilização são oposições formais, mas não se excluem, o que significa que não se trata de uma mera permutação de uma forma pela outra.

A educação, neste contexto, ainda que muitas vezes no plano da retórica, assume uma posição estratégica, posto ser de fundamental importância para a coesão social e a regulação social. Historicamente atrelada ao capitalismo e em conformidade com o atual regime de acumulação flexível, assume especificidades e sofre alterações tanto no seu conteúdo quanto na sua forma. As reformas educacionais em todo o mundo, longe de ser apenas um processo objetivo ligado às alterações administrativas na gestão das instituições, estão inseridas numa dimensão mais ampla.

A perspectiva de que a educação na sua função social deve subordinar-se às demandas do capital tem se naturalizado nas últimas décadas e parece disseminada com uma força avassaladora, sem o devido aprofundamento sobre os seus significados e implicações. Desse ponto de vista, tomando-se como referência o quadro de análise delineado sobre o processo de regulação, não há como não inquirir sobre o significado e o conteúdo das atuais reformas pelas quais vem passando a sociedade em todas as esferas, nas suas mais diversas instituições e, de modo particular, nos sistemas educacionais e nas escolas.

Com o fim de apreender os vínculos entre o papel da educação e o processo de produção e reprodução da sociedade, Popkewitz (1997) desenvolveu importante estudo sobre o processo de reformas na educação americana. Nele buscou identificar os princípios sociológicos e epistemológicos que fundamentaram as reformas, compreendidas pelo pesquisador como parte fundamental do 
processo de regulação social. No referido estudo, ele trata das amplas relações estabelecidas pela reforma, que compreendem desde a organização das instituições até as orientações condicionantes das ações dos indivíduos. Considerada como ponto estratégico da modernização das instituições, a reforma educacional transmite mais do que informações sobre novas práticas de escolarização. Na ótica do autor, ela atua na formação de valores, hábitos, disciplina e em todo processo que envolve a construção de um novo padrão de regulação social.

Partindo dos pressupostos teóricos da regulação, Popkewitz (1997) propõe-se a compreender a especificidade da reforma norte-americana. Contudo, suas análises permitem identificar pontos comuns e recorrentes na reforma educacional que vem sendo realizada em diversos países do mundo ocidental. A dinâmica de redefinição do papel do Estado, a reformulação do trabalho profissional associada a padrões burocráticos e técnicos, a organização do conhecimento vinculado a aspectos maiores da transformação social e do poder, a noção evolucionista naturalizada e pragmática do progresso e a inversão entre meios e fins são elementos que não se restringem apenas ao contexto americano.

Diferentemente de períodos anteriores, quando era vista apenas como parte do desenvolvimento maior da sociedade, a escola, no contexto dos complexos processos de regulação social em curso desde as últimas décadas do século XX, assume um papel estratégico, passando a ser vista como instituição capaz de corrigir as desigualdades e de promover a transformação social. A importância de estudos como o de Popkewitz reside no fato de demonstrar que a materialização das reformas educacionais e das consequentes mudanças na organização dos sistemas educacionais têm na escola o seu lócus fundamental. Esta, por sua vez, não se descola das mudanças ocorridas no plano da macroestrutura econômica, política e cultural. Logo, mais do que mera consequência das mudanças no quadro mais amplo do atual processo de acumulação capitalista, as reformas educacionais são compreendidas como constitutivas desse processo e podem ser percebidas como força expressiva na regulação e sustentação do atual processo de acumulação capitalista.

Nesse sentido, partindo da compreensão de que os sistemas de ensino e consequentemente as escolas constituem instrumentos importantes para a viabilização do processo de regulação da sociedade, faz-se necessário reformá-los e adequá-los aos moldes do novo regime de acumulação. Desse modo, é possível compreender o processo de regulação social capitalista na sua relação com as alterações no modelo de gestão da produção, e sua construção como resultante de um amplo movimento de reformas, que inclui, fundamentalmente, a reestruturação do Estado e o delineamento de uma agenda globalmente estruturada para a educação (DALE, 2004). 


\section{As novas formas de regulação das políticas educacionais}

Diante do exposto, torna-se necessário, então, compreender os processos de regulação em sentido stricto, ou seja, referindo-se às consequentes mudanças pelas quais vêm passando os sistemas escolares e a escola no contexto do que tem sido denominado por novas formas de regulaşão das políticas educacionais.

Para tanto, cabe recuperar as considerações feitas por Barroso (2006, p. 13) sobre o que denomina de teoria da regulação na análise das políticas públicas. Nessa questão, identifica a associação da regulação com a abordagem designada por "sociologia política da acção pública" sobre a qual destaca, por um lado, "a necessidade de apreender o Estado pela sua acção" e, por outro, de forma complementar, "a necessidade de apreender a acção do Estado através dos seus instrumentos". Sobre a importância dessa primeira perspectiva, valendo-se dos estudos desenvolvidos por Muller (2000 apud BARROSO, 2006, p. 13), o autor chama a atenção para a possibilidade de compreender o Estado não apenas com base em suas determinações, mas também em seu funcionamento. De acordo com ele, isso implica abrir mão de uma visão do Estado como um todo monolítico em troca de uma visão mais pormenorizada. A segunda perspectiva remete à noção de "instrumento de acção pública", conforme concebida por Lascoumes e Le Galés (2004 apud BARROSO, 2006). Barroso ressalta a necessidade de se perceber a forma como ocorrem atualmente "[...] as mudanças nas políticas públicas e o papel que os novos modos de regulação desempenham na reorganização do Estado e das suas formas de governo" (BARROSO, 2006, p. 13-14).

Com base nesse referencial e nas análises desenvolvidas no contexto do projeto de investigação realizado em cinco países europeus sobre a emergência de novos modos de regulação das políticas públicas, Barroso (2006) identificou, dentre outras mudanças relativas ao papel do Estado no contexto da regulação, a gradativa substituição de um "[...] controlo directo e a priori sobre os processos, por um controlo remoto, e a posteriori baseado nos resultados" (BARROSO, 2005, p. 732). Contrapondo-se à administração pública de controle burocrático, tradicionalmente caracterizada por normas e regulamentos, o autor chama a atenção para a utilização do termo regulação em oposição à regulamentação. A despeito de não ser esta uma distinção rigorosa, posto que não se excluem, o autor acrescenta que

[...] a 'regulação' (mais flexível na definição dos processos e rígida na avaliação da eficiência e eficácia dos resultados) seria o oposto da 'regulamentação' (centrada na definição e controlo a priori dos procedimentos e relativamente indiferente às questões da qualidade e eficácia dos resultados). (BARROSO, 2006, p. 63-64). 
O estudo desenvolvido por Barroso, ainda que num contexto muito diverso do brasileiro, demonstra certa generalização dos programas de reforma, fundamentalmente no que tange à submissão das políticas educacionais a uma racionalidade economicista. Nessa ótica, modelos de gestão empresarial passam a ser referência para as instituições escolares e seguem a mesma lógica os sistemas de avaliação centrados nos resultados. A despeito disso, o processo de regulação das políticas educativas não deve ser compreendido numa perspectiva linear; ao contrário, trata-se de um processo complexo e contraditório cuja apreensão deverá articular a particularidade local em relação aos processos sociais mais amplos, no esforço de apreender a regulação como totalidade, ou seja, na sua materialidade lógica e histórica.

A disseminação do conceito de regulação no âmbito educacional é relativamente recente. A ampliação dos estudos e pesquisas em torno da instituição de uma nova regulação política, social e econômica, no âmbito da reforma do Estado e de suas relações com as políticas educativas, tem tido lugar em vários países e constitui um campo fértil de investigação também no Brasil. De acordo com Oliveira (2005), os trabalhos produzidos no país, especificamente sobre esta temática, datam de meados da década de 1990. A autora ressalta as evidências da emergência de uma nova regulação nas políticas educacionais no contexto brasileiro: por meio da centralidade atribuída à administração escolar, que situa a escola como núcleo do planejamento e da gestão; do financiamento per capita; da ampliação dos exames nacionais de avaliação; e dos mecanismos de gestão que pressupõem a participação da comunidade. Sobre essa última questão, observa ainda que o forte apelo à descentralização administrativa, financeira e pedagógica, acrescido da ideia de maior autonomia da escola e da ênfase no trabalho coletivo, foi acompanhado de certa padronização dos procedimentos administrativos e pedagógicos (OLIVEIRA, 2005, 2007).

Dourado (2007), ao analisar a lógica e os limites presentes no Plano de Desenvolvimento da Escola, no Programa Dinheiro Direto na Escola e no Programa de Fortalecimento dos Conselhos Escolares, destaca o caráter ambíguo presente no direcionamento das políticas de organização e gestão da educação básica e, de modo específico, nos programas citados. Segundo o autor, a ambiguidade expressa no conjunto de programas evidencia-se, de um lado, no apelo ao caráter democrático e inclusivo e, de outro, na ênfase gerencial e produtivista. Disso resulta ainda o descompasso entre o proposto e o efetivado e a naturalização da fragmentação e desarticulação das políticas nos sistemas e unidades escolares. Verifica-se, ainda, que as reformas no campo da gestão educacional têm adotado cada vez mais elementos da lógica empresarial, que, na maioria das vezes, têm servido para velar e legitimar a continuidade de antigas configurações de poder. A novidade na forma abriga o antigo conteúdo, que 
aparece revestido com princípios, ditos mais modernos, eficientes e de melhor qualidade. Para Dourado (2007, p. 926):

Vivencia-se, no país, um conjunto de ações, de modo parcial ou pouco efetivo, sob a ótica da mudança educacional, mas que, de maneira geral, contribui para desestabilizar o instituído, sem a força política de instaurar novos parâmetros orgânicos à prática educativa.

Esse processo é recorrente no que se refere ao conjunto das políticas e programas que propõem reestruturar a gestão e a organização da educação básica. Esse conjunto de políticas articuladas às reformas do Estado tem se constituído em novas formas de regulação na educação, balizadas a partir dos anos de 1990, conforme se tentou evidenciar.

\section{Regulação das políticas educacionais e os seus desdobramentos em novas formas de organização da escola}

No contexto das reformas empreendidas no Brasil nas últimas décadas e, consequentemente, da incidência de novas formas de regulação das políticas na educação, particularmente no campo da gestão, tem-se em contraposição ao sistema de organização da escola em séries a emergência das propostas de organização da escolaridade em ciclos. Anunciando romper com os processos de exclusão, sobretudo por meio da flexibilização dos tempos e espaços na escola, as propostas se inscrevem na tentativa de superação da organização seriada e dos problemas dela advindos. Destacam-se, neste caso, os que se referem à exclusão provocada pela reprovação e evidenciada nas altas taxas de evasão e distorção entre a idade e o nível de escolaridade.

A denominação ciclos, de acordo com Mainardes (2009a), já era encontrada na década de 1930 "na Reforma Francisco Campos (década de 30) e na Reforma Capanema (Leis Orgânicas do Ensino - 1942/1946, p. 28) e era utilizada para designar o agrupamento dos anos de estudo". Como forma de designar etapas de escolaridade já estava presente na primeira Lei de Diretrizes e Bases da Educação Nacional - LDB n 4.024/61 (BRASIL, 1961).

De acordo com Barretto (2008), inúmeras são as experiências que desde a metade do século passado têm gestado os ciclos como modalidade de escolarização não seriada. De acordo com a autora, na tentativa de responder ao desafio de assegurar a todas as crianças o direito à educação, essa forma de organização tem incorporado na sua fundamentação "algumas das propostas mais avançadas do ideário educacional contemporâneo" e se aliada à defesa do direito a uma educação de qualidade. 
Contudo, essa "nova" forma de organização da escola em ciclos tem sido preconizada, de um lado, pelas políticas públicas oficiais que, por meio de demonstrativos estatísticos, têm incentivado a sua adoção, e, de outro, pelo ideário de uma educação democrática e inclusiva, que sob a justificativa da garantia do direito ao acesso, à permanência e a um desenvolvimento integral do aluno advoga em seu favor. Ambos os lados proclamam a flexibilização dos tempos e espaços na escola, organizados não mais em séries anuais, mas em ciclos, períodos semestrais, grupos com base na idade, na competência e em outros critérios ${ }^{1}$. É fundamental destacar, contudo, que as proposições que se autodenominam de ciclos apresentam, também, diferenças substantivas no que concerne à concepção dos ciclos, ainda que apresentem vários aspectos comuns no que se refere, sobretudo, à organização, à gestão e à avaliação.

Assim, coube investigar, a partir do contexto local, os princípios teóricos e as determinações históricas constitutivas das mudanças na organização da escola em ciclos e compreender em que sentido se configuram nos marcos regulatórios das políticas educacionais ou, se diferente disso, as propostas de organização da escola em ciclos podem, em alguma medida, representar um contraponto aos processos hegemônicos de regulação em curso.

No contexto brasileiro intensificou-se o processo de reformas que se configuraram como resposta às orientações de organismos internacionais, especialmente com relação à reestruturação do papel do Estado no que se refere às políticas públicas, particularmente às da educação. Constitutivas desse cenário as propostas de organização dos tempos escolares em ciclos, bem como a adoção de medidas como aprovação automática, progressão continuada e aceleração da aprendizagem, já não se configuram mais como programas alternativos restritos a alguns municípios.

Entretanto, para além de ter se desenvolvido como uma diretriz política oficialmente presente na Lei de Diretrizes e Bases da Educação LDB, 9.394/96 (BRASIL, 1996), nas orientações do MEC, especificamente nos Parâmetros Curriculares Nacionais, outra via de expansão da reorganização do ensino em ciclos tem se apresentado na sua caracterização como alternativa para inclusão social e buscado se distinguir do que se convencionou chamar de via oficial: os ciclos de formação e desenvolvimento humano. Essa forma de organizar o ensino em ciclos ganhou expressão fundamentalmente por meio de experiências realizadas em alguns municípios governados pelo Partido dos Trabalhadores (PT). Entre essas experiências, destacam-se a Escola Cidadã em Porto Alegre e a Escola Plural em Belo Horizonte.

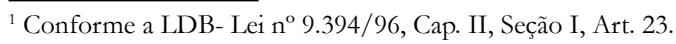


As propostas de organização da escola em ciclos buscam romper com as interrupções provocadas pela reprovação, instaurando assim um processo mais flexível e contínuo na organização do currículo, nos processos de avaliação e de gestão da escola. Em linhas gerais podem ser caracterizadas pela adoção de uma nova organização temporal, não mais em séries anuais, mas em ciclos que podem ter uma duração variável, ou seja, ciclos curtos, cuja duração pode ser de dois ou três anos, ou ciclos longos, cuja duração varia de quatro anos ou mais².

Em virtude das diferenciações e do grau de abrangência das mudanças propostas e implementadas, pode-se afirmar a existência de várias abordagens e formas de organização da escola sobre a mesma denominação de ciclos. Confirmando essa perspectiva, Mainardes (2009a) caracteriza o conjunto das experiências de escolaridade em ciclos no Brasil, por seu caráter radical, moderado ou conservador em relação à seriação. Nesse sentido, atribui ao regime de progressão continuada um caráter mais conservador em virtude das limitadas mudanças implementadas e pelo pequeno grau de diferenciação em relação à seriação, sendo esta modalidade adotada pelas redes estaduais de São Paulo, do Rio Grande do Sul, do Mato Grosso do Sul e pelas redes municipais de São Paulo, Araçatuba (SP), São José dos Campos (SP), São Vicente (SP) e Queimados (RJ), entre outras. As propostas denominadas de ciclo de aprendizagem apresentam, segundo o autor, um caráter moderado em razão dos avanços e mudanças apresentadas e podem ser encontradas nas redes municipais de Curitiba (PR), Ponta Grossa (PR), Olinda (PE), Pesqueira (PE); Recife (PE), Salvador (BA), São Luis (MA), Salto (SP), Ilhéus (BA). Quanto às experiências mais inovadoras e de caráter mais radical, encontram-se as propostas de organização do ensino em ciclos de formação que, de acordo com o autor, além de mais complexas que as demais exigem para a sua operacionalização uma reestruturação profunda do sistema escola, com destaque para as experiências da Escola Plural em Belo Horizonte e para a Escola Cidadã de Porto Alegre, consideradas pioneiras nesta modalidade de organização. Outras redes têm seguido as suas proposições e formas de organização, tais como: as redes estaduais de Mato Grosso e do Ceará (em algumas escolas), redes municipais de Araraquara (SP), Belém, Cuiabá (Escola Sarã), Goiânia, Rio de Janeiro, Vitória da Conquista (BA), Criciúma (SC) e Indaial (SC).

As três perspectivas se diferenciam no grau de flexibilização adotado. Nessa perspectiva, cabe enfatizar que, além de não haver um padrão consagrado de organização do ensino em ciclos no país, essas propostas têm apresentado constantes oscilações e recorrentes alterações ao longo do seu desenvolvimento, o que dificulta sobremaneira o seu delineamento. A ausência de continuidade é constante nos processos de implantação e implementação de políticas nos sistemas educacionais brasileiros e se deve, em grande parte, a mudanças no

\footnotetext{
${ }^{2}$ Para um maior aprofundamento sobre os fundamentos da escola em ciclos, ver Mainardes (2009a).
} 
poder executivo estadual e municipal e fundamentalmente a divergências político-partidárias.

No que tange ao currículo, à avaliação e à gestão, esta flexibilização pode variar em maior ou menor grau se comparada à estrutura de organização seriada. Nesse sentido, a partir do que tem sido indicado pela literatura e por muitos dos defensores dessa forma de organização da escola, quanto maior o grau de flexibilização, diferenciação e distanciamento em relação à forma de organização seriada, maior o avanço e a possibilidade de sucesso. Pode-se afirmar que a flexibilidade tem se constituído em princípio comum a todas as propostas, a partir do qual se estabelecem as diversas possibilidades e as variadas formas de organização.

Tal princípio tem maior expressão, especificamente no que se refere aos mecanismos de aprovação/reprovação. No que se refere à reprovação, é importante ressaltar a recorrência do termo retenção em sua substituição, o que indica a adoção de mecanismos mais sutis no interior da escola, em contraposição à rigidez da antiga regulamentação. Com essa perspectiva, a eliminação da reprovação passa a constituir-se no meio essencial de superação dos antigos problemas, como a repetência, a evasão e a distorção entre a idade e a etapa de escolarização.

Ademais, no âmbito do processo de flexibilização da avaliação reside a maior polêmica em torno da organização em ciclos. Se de um lado tem-se a reprovação como regulamentação e legitimação do modelo de organização da escola em séries, de outro tem-se a aprovação (total ou parcial) que passa a legitimar a flexibilização do novo modelo de organização da escola em ciclos ${ }^{3}$. Entretanto, situa-se nesse contexto a distinção e, por vezes, a contraposição entre as propostas de organização em ciclos, as propostas de progressão continuada e a promoção automática. Pressupõe-se desse modo que, na organização da escola com base nos ciclos do desenvolvimento humano, a reprovação seja completamente eliminada; nas propostas de progressão continuada a reprovação poderá ocorrer ao final de cada ciclo e nas redes de ensino que adotarem a aprovação automática, como o próprio nome já indica, a reprovação também deverá ser eliminada.

\footnotetext{
${ }^{3}$ É interessante observar que a discussão acerca da temática da reprovação foi bastante evidenciada na década de 1950. Fernandes (2000), por meio da revisão bibliográfica de artigos publicados sobre a temática na RBEP durante a referida década, afirma haver uma semelhança dos fundamentos encontrados nos atuais discursos e documentos sobre a organização da escolaridade em ciclos e da progressão continuada, aos fundamentos e discursos daquela década. De acordo com a autora, Juscelino Kubitschek em discurso proferido em 1957 defendia a promoção automática e com o enaltecimento de experiências estrangeiras, associando-a à ideia de progresso. Ademais, a ideia da promoção automática como uma medida econômica e eficaz também já se fazia presente no referido discurso. Ainda segundo a autora, surgem nesse período estudos sobre o fenômeno da reprovação e recomendações de medidas para a sua eliminação com base em modelos estrangeiros, particularmente o da Inglaterra.
} 
Condicionadas ao princípio da flexibilidade, dentre outras mudanças propostas, cabe citar: 1) a introdução da idade cronológica e das fases do desenvolvimento humano (infância, pré-adolescência e adolescência) como critério - único ou associado ao rendimento escolar - para a organização das turmas e admissão da matrícula; 2) novas formas de organização do conhecimento e seleção dos conteúdos, com ênfase na realidade e vivência dos alunos; 3) novas metodologias, como a inserção da pedagogia de projetos, complexos temáticos, currículos em rede, temas geradores, currículo por objetivos, habilidades e competências, pedagogia diferenciada, entre outros; 4) nova perspectiva de avaliação, com a valorização dos aspectos subjetivos em detrimento dos quantitativos e dos instrumentos descritivos em substituição às notas e conceitos; 5) formulação e adoção de diversificadas formas de atendimento no processo ensino-aprendizagem, como a recuperação paralela, turmas de progressão, turmas de aceleração, laboratório de aprendizagem, reagrupamento dos alunos, plano didático de apoio, turmas de apoio no contraturno etc. 6) a tentativa de uma organização menos hierárquica e a implementação de uma gestão democrática da escola com particular ênfase para a realização de um trabalho coletivo.

Em virtude das diferenciações e do grau de abrangência das mudanças propostas e implementadas, pode-se afirmar a existência de várias abordagens e formas de organização da escola sobre a mesma denominação de ciclos. Da mera aprovação automática ao agrupamento de séries ou, ainda, a adoção da aprovação acompanhada de outros mecanismos, todas, (auto) denominadas ciclos. $\mathrm{Na}$ perspectiva dessa polissemia conceitual, observam-se, ainda, propostas que se autodenominam ciclos, ciclos de formação, ciclos de aprendizagem, ciclos escolares, ciclos didático-pedagógicos, ciclagem, ciclo básico, dentre outras ${ }^{4}$.

Dessa forma, por caminhos diversos, a expansão das propostas de organização da escolaridade em ciclos vem se configurando nas últimas décadas como uma realidade contraditória. Não obstante as diversas perspectivas, tem denotado, por sua vez, finalidades e concepções político-ideológicas diferenciadas, projetos de sociedade distintos e muitas vezes antagônicos, o que evidencia a necessidade de mais estudos sobre a temática. Mainardes (2008), ao analisar teses e dissertações sobre a implementação da política de ciclos, identificou no conjunto da amostra analisada um número insuficiente de trabalhos com uma fundamentação teórica explícita e consistente sobre a temática. $\mathrm{O}$ autor atribui a existência desta lacuna a uma possível escassez na circulação de referenciais teórico-analíticos para análise das políticas educacionais no Brasil. Os resultados da investigação demonstraram que a maior parte dos trabalhos não articula o contexto micro ao da macropolítica, ou seja, a maioria dos trabalhos referem-se a processos locais e não se articulam ao sistema social mais amplo.

\footnotetext{
${ }^{4}$ Para um maior aprofundamento, ver Mainardes (2009b).
} 
Entretanto, é possível afirmar que muitas são as convergências no âmbito da proposição da escolaridade em ciclos, posto que, propalada no discurso, tal política busca ações orientadas para melhorar o acesso, a permanência, a inclusão e, sobretudo, o direito a uma educação de qualidade.

Nesse sentido, os discursos, as proposições, os indicadores, as políticas oficiais e muitas vezes a própria literatura têm apresentado a organização em ciclos como uma totalidade homogênea, ou seja, sem a devida apreensão de que essa forma de organização apresenta-se como uma política que agrega compromissos e interesses complexos, distintos e nem sempre explícitos e articulados de forma evidente. A tomar por referência as mudanças concernentes a um novo padrão de regulação social e que tem a escola como importante instrumento, cabe investigar, na particularidade que constitui cada proposta, até que ponto corresponde às novas formas de regulação das políticas e quais as possibilidades e perspectivas para a constituição de um projeto de escola pública, justa, igualitária e voltada para a formação humana.

Ademais, a intensificada crítica à escola tradicional é recorrente e proporcional à ênfase dada à flexibilização das estruturas e dos processos de organização da escola. Entretanto, ainda que haja concordância e legitimidade quanto à necessidade de mudanças na escola tradicional, que durante décadas foi privilégio de classe, cabe questionar, a despeito disso, o que esta escola guarda de tão nocivo a ponto de mobilizar, de forma consensual, diferentes forças, no contexto nacional e internacional, na luta em defesa de sua extinção. Estas são questões cujas respostas extrapolam os limites deste trabalho. Contudo, caberia investigar se a rigidez tão combatida na forma de organização seriada não diz respeito também à "tradicional crítica" que essa mesma escola foi capaz de elaborar acerca da estrutura de classes que sustenta a exploração capitalista em curso no mundo. Cumpre saber se não estaria no rigor da crítica a estrutura maior a ser combatida e flexibilizada.

A retórica sobre a necessidade de mudanças na educação estaria, de acordo com Miranda (2005), nos pressupostos subjacentes à racionalidade reformista da educação contemporânea. Nessa perspectiva, a autora identificou que as propostas de organização da escolaridade em ciclos de formação, muito mais do que a proposição de mudanças na organização dos tempos e espaços na escola, tratam fundamentalmente de modificar a compreensão de educação em seu sentido social mais amplo. De acordo com ela, encontra-se em curso nas propostas uma nova maneira de conceber a educação pública, cujas implicações poderão comprometer o destino de toda uma geração de crianças e adolescentes. Ademais, a organização com base na faixa etária ou etapas do desenvolvimento e, sobretudo, a mudança no conceito de reprovação, com a retirada dos mecanismos de aprovação/reprovação, altera o próprio conceito de escola. 
A autora acrescenta ainda que a grande aposta da reforma da escolaridade em ciclos incide sobre a mudança na cultura de alunos, professores, gestores e pais, ou seja, para além das mudanças estruturais, trata-se de alterar o cotidiano de alunos e professores. A despeito de considerar as distinções apresentadas por alguns autores acerca dos ciclos e da progressão continuada, Miranda (2005) adverte para o risco de que, ao final do processo, não seja possível distinguir as decorrências e implicações dos dois modelos, identificando como ponto comum nos dois projetos "provavelmente o caráter reformista da proposta, a despeito de todos os limites estruturais que tal perspectiva inexoravelmente contém, seja ela de caráter liberal ou social-democrata” (MIRANDA, 2005, p. 647).

Compreendendo essa forma de organização como uma política e, portanto, referida a uma particularidade histórica e ao contexto mais amplo das mudanças nas formas de regulação social, política e econômica, faz-se necessário alcançar as suas inúmeras possibilidades e limitações. Nesse contexto, é necessário buscar, nas diferenciações quanto à forma de organização, quanto à concepção, quanto à possibilidade de efetivação nas diversas redes de ensino do país, as suas reais finalidades e a que correspondem. Cabe aprofundar a análise no sentido de apreender ainda, na complexidade que envolve a questão, que compromissos agregam as propostas e a que interesses se vinculam, fundamentalmente no que se refere aos processos de regulação do Estado.

\section{A organização da escola em ciclos em Goiânia: novas formas de regulação? 5}

Ao tomar a organização da escola em ciclos como uma política no sentido stricto da ação estatal, ou seja, como uma política de governo que pode se configurar numa política de regulação em âmbito local, deve-se considerar que ela também se encontra, em maior ou menor grau, submetida às formas de regulação das políticas forjadas no sentido lato da ação do Estado. Neste sentido, a organização da escolaridade em ciclos em Goiânia pode ser compreendida como uma política demarcada duplamente por processos regulacionais.

A implantação da proposta de organização em ciclos na rede municipal de educação de Goiânia ocorreu sob a gestão do Partido da Social Democracia Brasileira (PSDB) no período de 1997 a 2000. Terminada essa gestão, a condução do executivo municipal coube ao Partido dos Trabalhadores (PT), no período de 2001 a 2004. Em seguida uma nova alternância político-partidária levou o Partido do Movimento Democrático Brasileiro (PMDB) a assumir a gestão de 2005 a 2008, com um segundo mandato iniciado no ano de 2009. Desse modo, coube

\footnotetext{
${ }^{5}$ Parte das análises aqui desenvolvidas foi apresentada no IV Encontro Estadual de Didática e Práticas de Ensino (ENDIPE), realizado em Goiânia em maio de 2011.
} 
analisar, no âmbito de três gestões, o conjunto de concepções, regras e preceitos que constituiu mudança e ruptura com o padrão de organização da escola seriada e o que configurou permanência dessa forma de organização. Buscaram-se, ainda, identificar as múltiplas ordenações teóricas, políticas, conceituais e legais referentes à organização dos tempos e espaços da gestão, do currículo e da avaliação.

\section{Desregulamentação do sistema seriado e regulamentação e implantação dos ciclos (1997-2000)}

Sob a direção do PSDB, teve início em 1997 uma gestão cuja pretensão maior era a "modernização" do sistema municipal de educação de Goiânia. Desse modo, caracterizar a implantação dos ciclos implicou, primeiramente, compreender o seu significado a partir do contexto inovador pretendido. Tomando-se por base o título dado à proposta - Escola para o Século XXI -, uma vez mais na história da Secretaria Municipal o intento era avançar rumo a um futuro cujas promessas de modernização pareciam mais próximas que as de outrora. Afinal, a chegada do novo século, o advento da informática e o acesso às multimídias têm provocado mudanças na maneira de conceber a escola.

O denominado Projeto Escola para o Século XXI, elaborado para ser implantado inicialmente em 40 escolas da rede municipal, assumiu notória expressão dessa gestão ${ }^{6}$ e passou a ser divulgado a partir de 1998 como se correspondesse à proposta político-pedagógica do então governo. A partir de então, os planos de ação apresentaram uma significativa alteração na dinâmica da gestão da secretaria, pois as diretrizes propostas para um projeto passaram a constituir os subprogramas de uma proposta maior de gestão. Dessa forma, o que era para ser uma experiência em um número restrito de escolas da rede municipal assumiu o caráter de programa de governo. As razões para essa alteração podem ser compreendidas como indicativas do resultado e do impacto que o Projeto teve no âmbito da rede e do município de Goiânia. Apesar de contar com uma forte resistência por parte dos professores, o projeto ganhou espaço na mídia, contou com recursos e apadrinhamento da UNESCO, criou laboratórios de informática em algumas escolas e, consequentemente, tornou-se protagonista com a ajuda de muito marketing, ganhando status de programa de governo (MUNDIM, 2002).

A gestão, embora fosse conduzida pelo PSDB, buscou referências nas experiências das secretarias municipais de Belo Horizonte e Porto Alegre, ambas sob a direção do PT, e fez a opção por organizar o ensino fundamental em três ciclos, ${ }^{7}$ a serem implantados nas escolas do Projeto Escola para o Século XXI:

\footnotetext{
${ }^{6}$ O Projeto Escola para o Século XXI foi bastante divulgado no período de sua implantação e esteve presente na mídia local: rádio, jornais, televisão.

${ }^{7}$ Consta no projeto inicial a previsão de implantação de quatro ciclos; no entanto, a partir de 1998, primeiro ano de implantação, houve a alteração para três ciclos.
} 
ciclo I - para alunos de 6, 7 e 8/9/ anos de idade; ciclo II - para alunos de 9 a 11/12 anos; ciclo III - para alunos de 12 a 14/15 anos.

A despeito das intenções da equipe que formulou a proposta e do marketing político criado em torno de sua implantação, é possível observar o distanciamento dos professores responsáveis pela efetivação da proposta nas escolas. Ainda que oferecesse ganhos, como o aumento do quantitativo de professores e do tempo para planejamento e estudo, além do acesso a laboratórios de informática e a tentativa de dinamizar os processos de gestão, currículo e avaliação, a proposta não foi capaz de ocultar o seu caráter pragmático e o comprometimento com a racionalização do tempo em favor de resultados na correção do fluxo escolar à medida que se configurou sem a efetiva participação dos docentes.

A organização do ensino fundamental em ciclos, nesse período, propunha às escolas integrantes do projeto, dentre outras alterações: 1) eliminação do sistema seriado, com a implantação dos ciclos segundo as fases do desenvolvimento humano; 2) reformulação curricular, ancorada nos princípios da inter e transdisciplinaridade; 3) eliminação da reprovação e mudança nos princípios e nos instrumentos de avaliação; 4) formação e capacitação continuada dos professores e qualificação profissional dos quadros da SME; 5) implantação de laboratórios de informática nas escolas; 6) modernização e reestruturação administrativa pelo processo de descentralização para as Unidades Regionais de Ensino (UREs). (GOIÂNIA, SME, 1998).

Propalada em 1993 como possibilidade de autonomia, de democratização e de desburocratização da escola, a proposta de descentralização para as Unidades Regionais de Ensino, foi reeditada em $1999^{8}$ como um instrumento de modernização administrativa que garantiria a eficiência do sistema e o fortalecimento dos aspectos gerenciais:

[...] todos os encaminhamentos dados na Secretaria Municipal de Educação, dentro do seu processo de modernização administrativa, se aliam às demandas da eficiência produtiva do sistema, no que tange ao fortalecimento dos aspectos gerenciais, com adoção de critérios de racionalidade, autonomia, participação da sociedade e descentralização de serviços. (GOIÂNIA, SME, 1999, p. 6, grifos nossos).

Em consonância com a lógica empresarial e com o modelo administrativo disseminado pelas reformas em curso no país desde o início dos anos 90, é possível identificar no conjunto de medidas propostas o desenvolvimento dos elementos constitutivos do que hoje pode ser compreendido como novas formas de regulação na educação. Isso fica evidenciado particularmente na ênfase dada ao processo de descentralização dos serviços, à autonomia das escolas e na flexibilização das estruturas, do modelo de organização seriado e dos processos pedagógicos, em contraposição a um maior controle e avaliação dos resultados.

\footnotetext{
${ }^{8}$ Data da proposta de descentralização analisada.
} 
É possível observar também que os documentos não apresentam de forma clara a concepção e os fundamentos teóricos orientadores das mudanças propostas na implantação dos ciclos nesse período. As justificativas apresentadas fazem referência à busca por solucionar os problemas de evasão, repetência e distorção idade/série e dos baixos índices de desempenho dos alunos na rede municipal. A falta de clareza acerca dos fundamentos, concepções e do conjunto de mudanças propostas decorre de uma prática, cada vez mais recorrente, de transposição de experiências, projetos e políticas de uma rede educacional para outra.

Entretanto, é preciso atentar para o fato de que o desconhecimento de várias instâncias, particularmente da escola, não foi impedimento para que mudanças substantivas fossem regulamentadas nas escolas e delas cobradas. No processo de regulamentação, especialmente os aspectos relativos ao currículo e à avaliação provocaram alterações significativas na lógica de organização seriada. Consequentemente, muitas das análises que foram feitas sobre esse período são convergentes em apontar o caráter de correção de fluxo à implantação dos ciclos em Goiânia. No entanto, a despeito de seu caráter pragmático direcionado para solucionar o problema do fracasso, essa proposta de organização da escola em ciclos apresentou-se também como alternativa de democratização e de luta contra as práticas de exclusão no interior do universo escolar. Essa possibilidade expressou-se em alguns aspectos, como: na regulamentação e eliminação da reprovação e na substituição dos instrumentos de avaliação quantitativa por fichas de avaliação e modelos de relatórios descritivos; na suspensão do currículo tradicionalmente organizado por disciplinas e a inserção dos objetivos para cada ciclo, a partir dos quais cada escola passou a organizar o seu próprio currículo; no aumento do quantitativo de profissionais e do tempo para o planejamento.

Outra característica marcante da organização em ciclos nesse período foi a fragmentação da rede municipal. A opção por uma implantação gradativa da proposta, ou seja, com o ciclo I em toda a rede e o ciclo II apenas em um grupo de escolas, passaram a existir, no interior da rede municipal, variadas formas de organização e, muitas vezes, em uma mesma escola havia a organização em série, ciclos e educação de jovens e adultos (EJA).

A busca por referências em outras redes municipais, as mudanças estruturais instituídas e as demais contradições internas ao processo de implantação da proposta estiveram ainda sob a influência mais ampla das políticas nacionais emanadas do MEC que, em certa medida, podem ser indicadoras da instituição de processos de regulação estatal. A proposta de organização da escola em ciclos em Goiânia, em grande medida, decorreu de várias influências e interferências, o que indica que os processos regulacionais mais amplos encontram ressonância nas regulações locais. Entretanto, é necessário atentar-se para o grau limitado de 
autonomia conferido às unidades escolares, para o poder de interferência das diversas instâncias e para as diversas formas como atuam. A par do discurso baseado na democratização da gestão e na diluição da esfera de decisão, ao que parece, a gestão não foi capaz de romper com as velhas práticas, permanecendo a escola sob o jugo do modelo administrativo gerencialista, assentado no cumprimento de regulamentos e demandas.

Contudo, o cariz modernizante que permeou a implantação do Projeto Escola para o Século XXI foi legitimado no quadro mais amplo das reformas e da modernização do Estado, constituindo uma primeira tentativa de regulamentação do princípio da flexibilidade também presente e propugnado pela LBB - Lei $\mathrm{n}^{\circ}$ 9.394/96 e pelos Parâmetros Curriculares Nacionais. Dessa forma, é possível afirmar que ocorreu na gestão do PSDB (1997/2000) a regulamentação de um processo que veio a ganhar materialidade na gestão subsequente $(2001 / 2004)$.

\section{Flexibilização do sistema seriado e a regulamentação e universalização dos ciclos: gestão (2001-2004)}

Para a gestão 2001-2004, assumiu o executivo municipal o ex-deputado federal, professor Pedro Wilson Guimarães. Para a Secretaria Municipal de Educação - SME, foi indicada a historiadora Walderês Nunes Loureiro, professora da Faculdade de Educação da UFG, que passou a contar na sua equipe com a participação e assessoria do professor Miguel Gonzáles Arroyo - ex-secretário da educação no município de Belo Horizonte entre 1993-1996 e um dos responsáveis pela implantação da proposta educacional Escola Plural -, além de professores da UFG e demais profissionais da SME.

Em âmbito local, a proposta aspirava à radicalização da democracia. Expressa como compromisso de campanha, congregou em seu entorno expressiva parcela dos educadores da cidade, que, a despeito do sombrio cenário político-econômico delineado em âmbito nacional e internacional, se engajaram de maneira expressiva na militância e luta em favor do que se propunha.

A rede municipal apresentava em 2001, no início da gestão, uma situação bastante diversa em termos de organização educacional. As 143 escolas municipais que ofereciam educação fundamental haviam implantado o ciclo I nas séries iniciais (alfabetização, primeira e segunda séries); desse total, 116 escolas trabalhavam com a seriação da terceira série em diante, $47 \mathrm{com}$ a organização no ciclo II e o ciclo III funcionando em 13 escolas. Diante dessa realidade e dos princípios propostos para a gestão, em 2002 os ciclos I e II foram reorganizados em todas as escolas da rede, tomando-se por princípio a equiparação da carga horária, a formação do coletivo e a faixa etária dos educandos. Em 2003, sob os mesmos princípios, ocorreu a extensão do ciclo III a todas as escolas da rede, o que indica a adoção total dessa política. 
Além das alterações acima relacionadas e de acordo com a Resolução CME/061, ocorreram ainda: extinção da retenção dos educandos na passagem de um ciclo para outro; supressão das classes de aceleração; matrícula inicial por faixa etária (com exceção dos alunos de 12,13, e 14 anos não alfabetizados, matriculados no ciclo II); alteração na periodicidade do registro da avaliação da aprendizagem, passando de bimestral para trimestral; modificação nos instrumentos de registro descritivo da avaliação; eleição do professor coordenador; realização de jornadas pedagógicas com temáticas diversificadas e troca de experiências entre docentes das unidades educacionais (GOIÂNIA, CME, 2003).

Comprometida com os propósitos da inclusão postos para essa gestão, a política de formação continuada dos profissionais da educação teve como mote central a valorização dos espaços de formação já existentes nas unidades educacionais, a exemplo do planejamento pedagógico, em que ocorrem " [...] as trocas de experiências, a reflexão, a pesquisa, o estudo e o repensar da prática pedagógica" (GOIÂNIA, SME, 2002, p. 27). Nesse sentido, uma das primeiras ações dessa gestão foi o redimensionamento da formação continuada vigente até então. Consta no documento Ações e Conceppõoes 2001-2004:

[...] Assim, a SME enseja uma formação continuada que compreenda o movimento de busca e inovação do fazer pedagógico nas diferentes unidades educacionais, a partir de seus próprios profissionais. Nesse sentido, a primeira iniciativa tomada pela equipe diretiva da SME foi a suspensão dos cursos de caráter convocatório e a realização da avaliação daqueles ditos de demanda espontânea, mecanismos que asseguram a possibilidade de ressignificação do papel da formação em serviço. (GOIÂNIA, SME, 2002, p. 27).

A política de formação adotada foi reconfigurada buscando romper com a vigente na rede municipal de educação, particularmente a partir da gestão anterior (1997-2000). A compreensão de que era necessário preparar os professores para a implantação da proposta de ciclos foi o que levou à constituição do Centro de Formação em 1998, composto por profissionais de diversas áreas. A destituição dessa proposta em 2001 ocorreu com base no entendimento de que a formação continuada prioritariamente deveria ocorrer por meio da troca de experiências entre as escolas, como um processo interno entre os professores que estivessem diretamente envolvidos na implementação da proposta.

Quanto à política de inclusão na rede municipal de educação, a gestão posicionou-se claramente contrária à perspectiva seriada tradicional, compreendida como seletiva e excludente. Em contraposição, propôs a construção coletiva de uma educação que considerasse as diferenças culturais e de ritmos de aprendizagem e que valorizasse a cultura popular, a realidade do aluno e sua condição de sujeito no processo educativo. Embora afirmasse considerar 
a autonomia das unidades educacionais, compreendia que autonomia não inclui o poder de excluir alunos, vetar matrículas, reprovar ou expulsar educandos, ou seja, que as “[...] instituições educacionais não têm o direito de ir contra o caminho percorrido de forma coletiva pelo conjunto da rede educacional e pelas conquistas históricas no campo da inclusão, como o direito à educação de todos [...]" (GOIÂNIA, SME, 2002, p. 12).

Essa premissa deveria, portanto, orientar a organização das instituições educacionais, seguindo uma "[...] lógica [na qual o educando fosse] o foco principal da reflexão e da prática pedagógica" por meio de “[...] iniciativas de subversão da lógica seletiva, excludente, utilitarista e credencialista, as quais têm orientado os sistemas educacionais do país" (GOIÂNIA, SME, 2002, p. 18). Tal organização tem nos ciclos o seu melhor exemplo.

A gestão da SME no período 2001-2004 buscou corrigir, em primeiro lugar, a fragmentação a que estava submetida a rede municipal de educação, uma vez que havia diferentes formas de organização em muitos casos dentro de uma mesma escola. Referenciada nas fases do desenvolvimento humano e ancorada no princípio da educação como um direito de todos, esta gestão regulamentou a eliminação da reprovação e intensificou na adoção da faixa etária como critério de organização das turmas. É possível afirmar que o impacto das mudanças incidiu sobre todas as escolas e mesmo as que já haviam implantado a proposta tiveram que se adequar aos novos critérios de organização. Da radicalidade das medidas propostas, é possível depreender que elas não ocorreram sem que houvesse resistência por parte das escolas e de diversos profissionais da rede. Sobre esse contexto, as opiniões são bastante divergentes e, por vezes, contraditórias, o que traduzem os embates entre os diferentes segmentos na efetivação da proposta na rede.

Quanto aos critérios adotados, a polêmica estendeu-se para além da SME, e as maiores críticas dirigidas a esta gestão referem-se às mudanças no processo de avaliação, interpretadas por muitos como a inserção da aprovação automática ${ }^{9}$ na rede municipal. A histórica polêmica em torno da aprovação/reprovação, longe de ser equacionada, encontra ressonância no debate local sobre a organização em ciclos que, a despeito da justificativa pedagógica de representar o desenvolvimento integral do sujeito, parece justificar-se a partir de um posicionamento político. Tal perspectiva acaba reduzindo, por vezes, o debate a uma discussão da avaliação sem enfrentar a complexidade presente no tocante a melhoria do processo ensino-aprendizagem e nas formas de organização e gestão e seus desdobramentos.

\footnotetext{
${ }^{9}$ Denomina-se aprovação automática a suspensão da reprovação em qualquer etapa no interior de um mesmo ciclo ou na passagem e ao final dele.
} 
Em síntese, embora tenha gerado controvérsias e divergências, as ações implementadas por esta gestão provocaram alterações significativas no interior das escolas. São recorrentes as afirmações que lhe atribuem a tentativa de implantação de uma proposta que, embora tenha apresentado um distanciamento entre a sua formulação e a efetivação, contribuiu para desestabilizar o modelo de organização seriado e inflexível, até então instituído, e para democratizar a escola.

O quadro delineado, com base nos documentos e na visão daqueles que contribuíram para a formulação e acompanhamento da proposta de organização da escola em ciclos nessa gestão, possibilitou apreender que o processo de desregulamentação da seriação, iniciado com a implantação dos ciclos na gestão anterior, foi ampliado às demais escolas de educação fundamental. Contudo, esse processo foi acompanhado de uma série de ações e medidas cujo eixo condutor foi a flexibilização da estrutura e do processo de organização do trabalho pedagógico na escola.

Em síntese ocorreu um processo de regulamentação, particularmente no que se refere aos seguintes aspectos: instituição de novos critérios para a organização das turmas; suspensão da reprovação no interior e na passagem de um ciclo para o outro; alteração nos instrumentos de avaliação por meio de fichas e de relatórios descritivos; organização do currículo por objetivos, cujo foco passou a ser o aluno; e constituição de uma gestão coletiva do trabalho pedagógico nas escolas. Esse conjunto de medidas, demonstrativo da opção política adotada e da universalização da organização em ciclos nas escolas da rede, sofreu alterações no contexto da gestão subsequente.

\section{A (re) regulamentação dos ciclos na rede municipal: gestão 2005- 2008}

No movimento de continuidade e ruptura presente na trajetória do município e da própria SME, inicia-se mais um período, com a volta de Iris Rezende Machado à cena política goianiense. A vitória do candidato peemedebista, de longa trajetória na vida política e com um histórico marcado pelos cargos que ocupou como vereador, prefeito, deputado, senador e ministro, expressa a força da tradição na política em Goiás. Assim, altera-se uma vez mais a configuração do executivo municipal e, por conseguinte, a direção dada à política educacional em curso na rede municipal. Nesta gestão, assumiu a SME a professora Márcia Pereira Carvalho.

Um dos jornais da época noticiou o fato sob o seguinte título: "Oriunda da rede privada de ensino, onde contam resultados e não ideologias, a nova secretária municipal de educação quer instituir no município o ensino de 
excelência” (BELÉM, 2005, p. 3). Conforme consta na matéria, a secretária vinha de uma carreira muito bem sucedida como professora e gestora na rede privada de ensino.

O início da gestão peemedebista foi marcado pela incerteza em relação à possível continuidade ou ruptura com a política de ciclos em desenvolvimento na rede municipal. Conforme relata a secretária na referida matéria, ao tomar posse foi convocada pelo Ministério Público para discutir sobre a aprendizagem na rede municipal de educação, posto que várias ações haviam sido protocoladas no órgão questionando a qualidade do ensino ministrado na rede. Sob a alegação de que havia alunos no ciclo III, correspondente à $8^{a}$ série, que não sabiam ler e nem escrever, o Ministério Público orientou que o processo de avaliação fosse imediatamente retomado com a instituição de provas no sistema.

Acrescente-se a esse fato, conforme relata a secretária, que "[...] uma das propostas de Iris Rezende, na campanha, era redimensionar a questão dos ciclos, debatendo seus defeitos e qualidades" (BELÉM, 2005, p. 3). Dessa forma, foram instituídas no primeiro ano desta gestão uma série de mudanças na proposta de ciclos em desenvolvimento, como esclareceu a secretária em entrevista:

Há escolas que implantaram os ciclos no Rio Grande do Sul, em Brasília, em Minas Gerais, em São Paulo. Em nenhuma delas o ciclo funcionou, infelizmente. Muitas pessoas da rede acham que o ciclo não vai dar certo, mas eu preciso de tempo para provar se ele vai ou não dar certo [...] Eu seria inconseqüente, já nesse ano letivo, se acabasse com os ciclos e voltasse com a seriação. Mexeria em tudo, inclusive na carga horária dos professores, no salário deles. (BELÉM, 2005, p. 3).

Conforme consta do documento Reorganização dos ciclos de formação $e$ desenvolvimento bumano na rede municipal de educação de Goiânia, aprovado pela Resolução do Conselho Municipal de Educação n ${ }^{\circ}$ 195, de 19 de dezembro de 2005 (GOIÂNIA, CME, 2005), as alterações na proposta foram balizadas pela I Avaliação dos Ciclos de Formação e Desenvolvimento Humano, que abrangeu 3.344 educandos do Ciclo I e 1.395 do ciclo II. De acordo com o Relatório Final, a exemplo do que vinha ocorrendo em grande escala com as avaliações do Sistema Nacional de Avaliação da Educação Básica - SAEB, da Prova Brasil e do Exame Nacional do Ensino Médio - ENEM, a SME instituiu, por meio do Núcleo de Avaliação e Pesquisa (NAP), o seu próprio sistema de avaliação de desempenho dos alunos no ensino fundamental em ciclos. A partir desse processo, ocorreu a reestruturação da proposta nos seguintes aspectos: a) processo de enturmação; b) mobilidade; c) freqüência; d) avaliação; e) redimensionamento do currículo.

Quanto à enturmação dos alunos, a proposta afirma a necessidade de assegurar a constituição de grupos com idades aproximadas. O processo deve 
ocorrer de maneira flexível, considerando, além da idade, o desenvolvimento sócio-histórico, cultural, afetivo e cognitivo do educando, bem como seu ritmo de desenvolvimento. Contudo, "[...] os educandos com idade de 12, 13 e 14 anos, não alfabetizados, serão enturmados no início do segundo ciclo, com garantia de permanência de três anos nesse ciclo" (GOIÂNIA, CME, 2005).

Em relação à mobilidade do educando dentro de cada ciclo, as alternativas propostas são de agrupamentos temporários, progressão, avanço e permanência. A proposta enfatiza que todos os educandos têm o direito a permanecer por três anos em cada ciclo, logo não há retenção no interior dos ciclos. Ressalta-se ainda que os educandos que apresentarem defasagem idade/ciclo serão atendidos por projetos específicos de trabalho, sob a supervisão da Unidade Regional à qual a escola está vinculada.

A avaliação passa a ser acrescida do aspecto quantitativo, ou seja, de um quadro de percentual e gráfico demonstrativo dos objetivos alcançados. Quanto ao currículo, passa de uma organização por áreas afins para uma organização por componente curricular, ou seja, por disciplinas. A frequência do educando, conforme a Lei de Diretrizes e Bases da Educação Nacional - Lei no 9.394/96, deverá ser de $75 \%$ do total de horas ou dias letivos em cada ciclo (GOIÂNIA, CME, 2005). Dentre outras ações implementadas por esta gestão, cabe ressaltar ainda a criação de dois Centros Municipais de Apoio à Inclusão (CMAI), cujo objetivo fundamental consiste em oferecer atendimento especializado por meio de uma equipe multiprofissional aos educandos que apresentem graves dificuldades no processo de aprendizagem.

Em linhas gerais, esta gestão (2005-2008), sob o argumento de que a rede não se apresentava devidamente preparada para a ampliação dos ciclos para todas as escolas, buscou um redimensionamento da proposta em pontos estratégicos. No processo de enturmação, ocorre a relativização da idade que passou a ser uma referência associada ao nível de conhecimento do aluno; a avaliação descritiva passou a incorporar dados e referenciais quantitativos e, após a experiência de aprovação total dos alunos, retornou a possibilidade de reprovação; o trabalho coletivo foi alterado pela redução no quantitativo de profissionais do ciclo e pela suspensão do planejamento semanal. A justificativa apresentada para a suspensão do planejamento semanal foi de ordem legal, baseada na exigência posta pela LDB - Lei $\mathrm{n}^{\circ} 9.394 / 96$ do cumprimento dos 200 dias letivos e das 800 horas de trabalho efetivo com os alunos. Há, contudo, quem defenda que a retirada do planejamento permitiu uma melhor racionalização do tempo na escola.

A proposta de formação desta gestão, ao que parece, sofre também uma reestruturação e retoma alguns dos pressupostos da proposta de formação instituída pela gestão do PSDB, particularmente no que diz respeito à retomada de processos de formação mais circunscritos à prática. 
De modo sucinto, foi possível perceber que a gestão 2005-2008 alterou muitas das medidas e ações implementadas pela gestão anterior, sobretudo aquelas que sinalizavam avanços nos processos de trabalho e nas dinâmicas de organização e gestão da escola. As justificativas e as próprias medidas e critérios adotados revelam o uso do discurso em defesa da melhoria da aprendizagem dos alunos como recurso para a afirmação do processo de "reestruturação pedagógica".

Nessa perspectiva, a proposta político-pedagógica enfatiza a necessidade de ações de monitoramento e avaliação do trabalho. A defesa da importância do acompanhamento e avaliação dos resultados no âmbito desta gestão pode ser compreendida como um traço característico e marcante da política adotada. Portanto, a preocupação e a ênfase na avaliação de resultados não são mera decorrência de um processo de intervenção externa, mas, mais que isso, trata-se de consentimento, adesão e alinhamento às políticas de avaliação procedentes do governo federal. Conforme esclareceu um dos integrantes desta gestão, trata-se da superação dos próprios parâmetros exigidos pelos sistemas de avaliação, particularmente no que se refere ao alcance de índices mais altos no IDEB - Índice de Desenvolvimento da Educação Básica.

Desse modo, foi possível traçar em linhas gerais o direcionamento dado à política de organização da escola em ciclos no âmbito dessa gestão.

Entretanto, a despeito das várias alterações ocorridas ao longo do desenvolvimento dos ciclos na rede municipal, o que em vários aspectos parece tratar-se de três propostas distintas, há uma demonstração de regularidade e complementaridade que confere identidade à organização dos tempos e espaços da escola em ciclos no município de Goiânia.

\section{Considerações finais}

Nesta análise foi possível compreender que vêm ocorrendo profundas modificações em decorrência das mudanças sociais, políticas e econômicas constitutivas de um novo padrão de regulação social, que, na esteira do desenvolvimento do capitalismo, tem repercutido nacional e internacionalmente. No contexto brasileiro, intensificou-se o processo de reformas configuradas como resposta e anseios das elites nacionais às orientações de organismos internacionais, especialmente com relação à reestruturação do papel do Estado nas políticas públicas, particularmente as da educação. $\mathrm{Na}$ área educacional, várias políticas, programas e ações vêm sendo implementadas. Destaca-se nessa dinâmica a efetivação de propostas de alterações nas formas de organização e gestão por meio da adoção de ciclos.

Ao tomar a organização da escola em ciclos como uma política no sentido stricto da ação estatal, ou seja, como uma política de governo que pode se 
configurar numa política de regulação em âmbito local, deve-se considerar que ela também se encontra, em maior ou menor grau, submetida às formas de regulação das políticas forjadas no sentido lato da ação do Estado. Neste sentido, a organização da escolaridade em ciclos em âmbito local pode ser potencialmente compreendida como uma política demarcada duplamente por processos regulacionais.

Os resultados do estudo e da investigação teórica e empírica levam à conclusão de que a combinação de diferentes fatores no âmbito da gestão e do trabalho escolar tem resultado num processo de reestruturação do trabalho, da estrutura e dos processos pedagógicos na escola. A flexibilização das normas regulamentares institucionalizadas na seriação, com as alterações na própria legislação da educação, resultou na mudança e flexibilização dos tempos e espaços da escola. Isso se deu particularmente no que se refere ao trabalho e ao papel do professor, à organização do currículo, à noção de conhecimento, às formas de avaliação e à própria forma de conceber a escola na sua função.

O presente estudo revelou a complexa e contraditória política de organização da escola em ciclos desenvolvida na rede municipal e o grande desafio para o enfrentamento de questões, como as difíceis e precárias condições de trabalho dos professores, a elevada distorção entre a idade e a escolaridade dos alunos, a possível não aprendizagem, dentre outras que, acrescidas às novas demandas imputadas à escola, urgem ser investigadas. Frente a essas constatações é possível inferir, a partir das determinações constitutivas da proposta de organização da escola em ciclos em Goiânia, a sua relação com a regulação das políticas educativas em curso nas últimas décadas e a sua correspondência às novas formas de regulação social. Isso permite dizer que a criação das condições para ampliar a dinâmica da esfera pública assim como a garantia dos direitos devem se pôr como horizonte a ser alcançado nas ações das instituições públicas e, em especial, naquelas que dizem respeito à educação.

\section{Referências}

AGLIETTA, M. Regulación y crisis del capitalismo: la experiência de los Estados Unidos. México: Siglo Veintiuno, 1979.

BARRETTO, E. S. As escolas com ciclos e seus resultados no processo ensino-aprendizagem. In: FETZNER, A. R. (Org.). Ciclos em revista - v. 4. Rio de Janeiro: WAK Editora, 2008. p. $195-212$.

BARROSO, J. O Estado, a educação e a regulação das políticas públicas. Educação \& Sociedade, Campinas, v. 26, n. 92, p. 725-751, especial, out. 2005. DOI: 10.1590/S010173302005000300002

- (Org.). A regulação das políticas públicas de educação: espaços, dinâmicas e actores. Lisboa: Educa/Unidade de I \& D de Ciências da Educação/Autores, 2006. 
BELÉM, E. Entrevista. Jornal Opção, Goiânia, 27 mar./02 abr. 2005. Disponível em: $<$ http://www.jornalopcao.com.br/index.asp?secao=Entrevistas\&idjornal=126>. Acesso em: 28 mar. 2009.

BOYER, R. A teoria da regulação: uma análise crítica. São Paulo: Nobel, 1990.

BRASIL. Lei n. 4024/1961, de 20 de dezembro de 1961. Estabelece as diretrizes e bases da educação nacional. Diário Oficial da União, 27 dez. 1961.

Lei n. 9394/96, de 20 de dezembro de 1996. Estabelece as diretrizes e bases da educação nacional. Diário Oficial da União, Brasília, 23 dez. 1996.

CHESNAIS, F. A mundialização do capital. São Paulo: Xamã, 1996.

DALE, R. Globalização e educação: demonstrando a existência de uma "cultura educacional mundial comum ou localizando uma agenda globalmente estruturada para a educação?". Educação \& Sociedade, Campinas, v. 25, n. 87, p. 423-460, maio/ago. 2004. DOI: 10.1590/ S0101-73302004000200007

DOURADO, L. F. Políticas e gestão da educação básica no Brasil: limites e perspectivas. Educação \& Sociedade, Campinas, v. 28, n. 100, p. 921-946, especial, out. 2007. DOI: 10.1590/S0101-73302007000300014

FERNANDES, C. O. A promoção automática na década de 50: uma revisão bibliográfica. Revista Brasileira de Estudos Pedagógicos, Brasília, v. 81, n. 197, p. 76-88, jan./abr. 2000. GOIÂNIA. Secretaria Municipal de Educação. Escola para o século XXI. Goiânia: SME, 1998.

Plano de ação 1999. Goiânia, 1999.

Ações e concepções (2001-2004). Goiânia, 2002.

. Conselho Municipal de Educação. Resolução n. 061/03. Alterações no projeto "Escola para o Século XXI". Goiânia: CME, 2003.

Resolução n. 195/05. Alteração na proposta político-pedagógica para a educação fundamental da infância e adolescência. Goiânia, 2005.

LIPIETZ, A. Miragens e milagres: problemas da industrialização no Terceiro Mundo. São Paulo: Nobel, 1988.

MAINARDES, J. A organização da escolaridade em ciclos no Brasil: uma análise de pesquisas sobre processos de implementação. Revista Brasileira de Política e Administração da Educação, Porto Alegre, v. 24, n. 1, jan./abr. 2008.

Escola em ciclos: fundamentos e debates. São Paulo: Cortez, 2009a. (Coleção questões da nossa época, v. 137).

A pesquisa sobre a organização da escolaridade em ciclos no Brasil (2000-2006): mapeamento e problematização. Revista Brasileira de Educação, Rio de Janeiro, v. 14, n. 40, p. 7-23, jan./abr. 2009b. DOI: 10.1590/S1413-24782009000100002

MAROY, C. Convergências e divergências dos modos de regulação numa perspectiva européia. In: BARROSO, J. (Org.). A regulação das políticas públicas de educação: espaços, dinâmicas e actores. Lisboa: Educa/Unidade de I \& D de Ciências da Educação/ Autores, 2006. p. 227-244. 
MIRANDA, M. G. Sobre tempos e espaços da escola: do princípio do conhecimento ao princípio da socialidade. Educação \& Sociedade, Campinas, v. 26, n. 91, p. 639-651, maio/ ago. 2005. DOI: 10.1590/S0101-73302005000200017

MUNDIM, M. A. P. A rede municipal de ensino de Goiânia e a implantação dos ciclos de formação (1997-2000). 2002. 126 f. Dissertação (Mestrado em Educação) - Faculdade de Educação, Universidade Federal de Goiás, Goiânia, 2002.

OLIVEIRA, D. A. Regulação das políticas educacionais na América Latina e suas conseqüências para os trabalhadores docentes. Educação \& Sociedade, Campinas, v. 26, n. 92, p. 725-751, especial, out. 2005. DOI: http: 10.1590/S0101-73302005000300003

Política educacional e a re-estruturação do trabalho docente: reflexões sobre o contexto latino-americano. Educação \& Sociedade, Campinas, v. 28, n. 99, p. 355-375, maio/ago. 2007. DOI: 10.1590/S0101-73302007000200004

POPKEWITZ, T. S. Reforma educacional: uma política sociológica-poder e conhecimento em educação. Porto Alegre: Artes Médicas, 1997.

Recebido em 10/12/2011

Versão final recebida em 01/05/2012

Aceito em 03/05/2012 